\title{
Development of an automatic pulling mechanism of probe plug in marine eXpendable BathyThermograph launching system
}

\author{
Chen Guangyuan', Lei Zhuo², He Haijing ${ }^{3}$ \\ Institute of Oceanographic Instrumentation, Qilu University of Technology (Shandong Academy of \\ Sciences), Shandong, China \\ Shandong Provincial Key Laboratory of Marine Monitoring Instrument Equipment Technology, Institute of \\ Oceanographic Instrumentation, Shandong, China \\ National Engineering and Technological Research Center of Marine Monitoring Equipment, \\ Qingdao, China \\ ${ }^{1}$ Corresponding author \\ E-mail: ${ }^{1}$ reebird0430@163.com, ${ }^{2}$ leizhuo2011@163.com, ${ }^{3}$ haijinghe@163.com
}

Received 25 October 2018; accepted 3 November 2018

DOI https://doi.org/10.21595/vp.2018.20341

Check for updates

Copyright $\mathbb{C} 2018$ Chen Guangyuan, et al. This is an open access article distributed under the Creative Commons Attribution License, which permits unrestricted use, distribution, and reproduction in any medium, provided the original work is properly cited.

\begin{abstract}
Marine eXpendable Bathythermograph (XBT) launching system is used to launch detecting probes into the ocean quickly and efficiently and has been researched for many years. The probes will measure the ocean parameters of depth and temperature during droppings which make the device with the merits of real-time, fast and wide spreading. The automatic pulling mechanism of probe plug is an important part of XBT automatic launching system which improves the shortcoming of hand-held launch method of XBT probe. This development mentioned a kind of automatic extraction mechanism for probe's plug fixed the probe. The lever is adopted here to magnify the tensile force in order to draw out the plug in limited stroke. That will make sure the full-automatic launching of expendable probes. In tests, the successful dropping rate is over $95 \%$ and save time over $50 \%$ more than hand-held method which prove the automatic extraction mechanism effect and reliable. The mechanism also can be used into various automatic launchers of expendable probes through a little configuration adjust. Its broad application prospect is viewed.
\end{abstract}

Keywords: XBT, automatic launch, plug pull, leveraged mechanism.

\section{Introduction}

Expendable bathythermograph (XBT) is used to measure the ocean temperature and depth for scientific investigation, environment monitoring and military oceanology $[1,2]$. It is a common device that used into ocean studies [3, 4]. XBT mainly consisted of three parts that is measuring probe, launching gun, and deck processing unit. In the objective marine area, the launching gun launches the probe into the ocean and there are connected by a transmission line. The probe decreased freely in the sea until the measurement finished by the disconnection of transmission line. During the decreasing, the sensors on the probe obtain the depth and temperature in real time. Those parameters are transmitted back to the deck processing unit via transmission line. The expendable system could make measurement during the sailing or anchoring. The research of XBT dated from 1960s and 1970s by Lockheed Martin Sippican Corporation [5] and TSK Corporation, respectively. Nowadays, their products have derived into 8 version numbered from T-4 to T-12 and been sold all over the world. The research and development of XBT in China has been realized for decades by institutions and colleges [6], such as National Ocean Technology Center [7], China Shipbuilding Industry Corporation, Xi'an Tianhe Defense Technology CO. Ltd, Institute of Oceanographic Instrumentation (Shandong Academy of Sciences) [8-10], and so on.

The measurement activities of ocean parameters processed thousands of times yearly. In the same trail, the drop of probes may be up to several hundreds. While one launching gun only can launch one probe for one time, that is very inefficient. The operators should stand beside the ship 
rail and hold the launching gun out of the ship in order to detach the probe from ship. The bad sea state will endanger the operators and hinder the measurement. Based on those shortcomings, we carried on a research of automatic launching system of XBT probes. After installing the probe bucket on the automatic launching system, we designed an automatic mechanism to pull the probe plug which fixed the probe in the bucket. That design is based on lever principle [11] and has not been retrieved in other researches yet. As a very important part, it makes the automatic launching system effective for continuous drops.

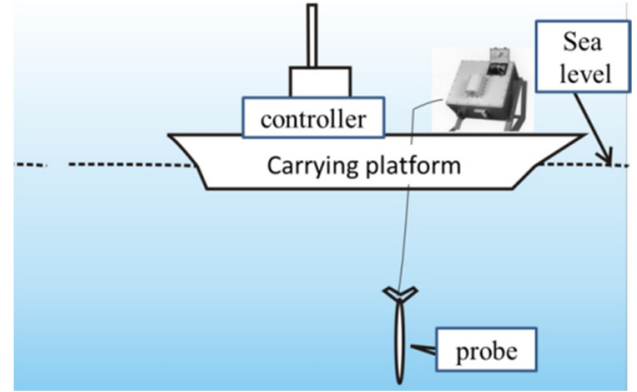

Fig. 1. Automatic multiple launcher for expendable probes

\section{Force analyses of plug introduction}

When the probe bucket installed on the automatic launching system, the forces pressed on the plug is shown in Fig. 2. The plug is shown as a triangle with a tail colored in red. The probe is hanged in the bucket through the hole at the probe tail by the plug. The probe inclines to the horizontal level with 45 degree. The plug handle is installed under the bucket downwards that is designed to make advantage of gravity. After enabling the launch, the plug would be pulled out under drawing force perpendicular to the supporting plane and plug gravity. Mechanic principle mentioned above necessitates the force analyses of the plug-in order to design the force application.

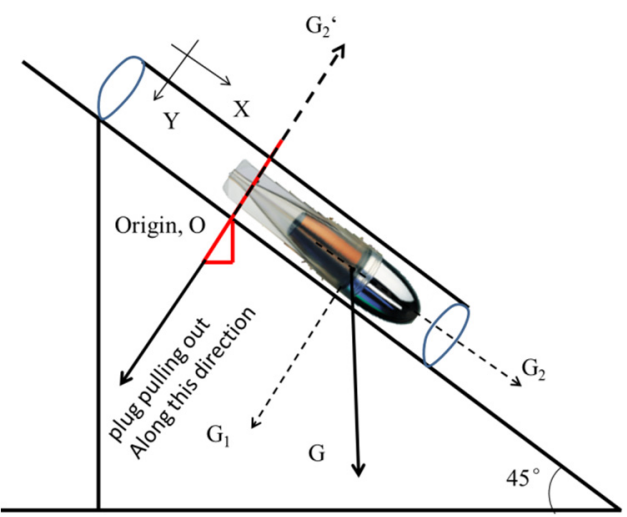

Fig. 2. Force analysis of the XBT probe latch

Cartesian coordinate system is rotated here, shown as Fig. 2. The $X$ axis is rotated to parallel to the supporter and positively directing to downward along the supporter. The $Y$ axis is perpendicular to the supporter and positively directing to downward along the normal vector of supporter. The origin $O$ is placed at the cross point of plug and supporting plane. In the new coordinate system, we analyze the forces pressed on plug.

The gravity of plug itself is negligible compared with the probe. Hence, in the pulling process, the gravity of probe, $G$, affects the plug as a main force. Along $X$ axis and $Y$ axis, $G$ could be 
separated into force vertical to the plane, $G_{1}$ and force parallel to the plane, $G_{2}$. At the original point, $G_{1}$ and $G_{2}$ pull down the plug vertical and along the plane, respectively. $G_{2}$ also make a compress on the plug which generates frictional force, $G_{2}^{\prime}$. $G_{2}^{\prime}$ directs to upwards and is perpetual to the supporting plane. This force keeps the plug from slipping down. According to force analyses, the magnitude of pulling force should be larger than that of $\left(G_{2}^{\prime}-G_{1}\right)$, which guarantee the plug be pulled out successively.

\section{Scheme design}

The automatic plug pulling mechanism was designed based on principle above and the real needs in field work. Lever structure is the kernel of this mechanism. An electromagnet contributes magnetism as original pull force, and then corporate with level to realize the fix, pull out and release of the probe plug. The mechanism converts the pull force into maximum within the minimum offset. This benefits the marine XBT launching system to be miniaturization.

\subsection{Design of automatic plug pulling mechanism}

The profile of the designed automatic plug pulling mechanism is shown in Fig. 3. The pulling procedure consisted of initial phrase, probe installation phrase and automatic pulling phrase. In the initial phrase, the upside of lever 1-2 flexibly connects with releasing mechanism 1-1. The upside of lever holds up the releasing mechanism and the supporting force is perpetual to their contact surface. The force directed up and magnitude is same as elastic force of the spring. In the probe installation phrase, the operator installs a XBT probe and bucket into the automatic pulling mechanism according to the direction shown in Fig. 2. The fixed plug in the probe push the flexible side of the connect mechanism to open under the manual thrust. The plug goes into the connect mechanism at that convenience. Then, the flexible side will turn off automatically by the force of internal spring. At this time, the plug is locked in the connection mechanism and the second phrase is finished. Especially, the shape of the connect mechanism is designed as a droplet which turn to be arc at the bottom and minimize the friction to plug.

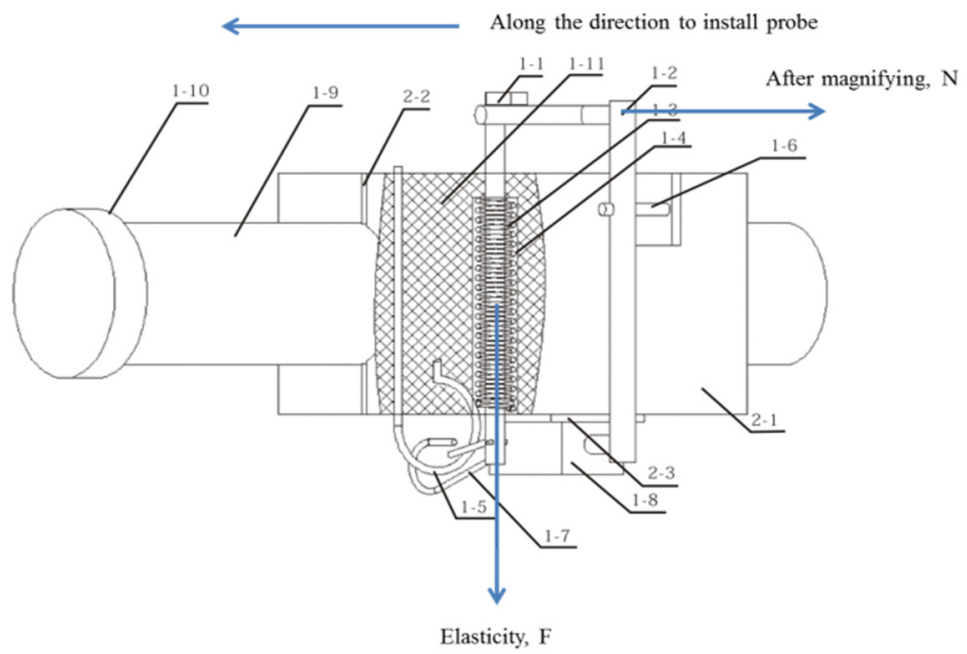

Fig. 3. The structure of automatic pulling mechanism: 1-1 releasing mechanism, 1-2 lever, 1-3 spring, 1-4 spring groove, 1-5 spring guide rod, 1-6 plug, 1-7 support frame, 1-8 binding mechanism, 1-9 electromagnet, $1-10$ probe groove, $1-11$ groove lid, $1-12$ profile of anchor block; 2-1 anchor block, 2-2 mounting groove of plug, 2-3 mounting rack of electromagnet

When the deck processing unit send the launch command, the automatic plug pulling mechanism initiate the automatic launching state. The mechanism electrifies the electromagnet 
(1-9), and the magnetic force increasing immediately and then make effect on the downside of the lever, 1-2. Through the leverage, the lever changes the force at the downside to a greater one at the upside, $N$. The force $N$ segregates the lever upside and release mechanism along the direction perpetual to the lever. By this time, the plug (1-6) is pulled out under spring elasticity, $F$.

\subsection{Release force analyses}

Choice of parameters of spring and the lever fulcrum are very important in the release mechanism, because of the space limitation in the whole XBT launching system where the automatic plug pulling mechanism installed in. We can calculate the spring parameters by Hooke's law easily. The method to determine the lever fulcrum is as follow.

During the pulling procedure, the upside of lever needs to conquer the friction made by the release mechanism (1-1) shown in Fig. 3. This friction is generated by the elasticity which spring presses to the release mechanism. Hence, designer could calculates the objective releasing force on the lever and connect mechanism from the elasticity produced after spring released. Considering the marine corrosion situation, the automatic pulling mechanism is made of stainless steels. Friction coefficient of this material is 0.3-0.4. According to equations as follow, we can derive the release force $(N)$, which ensures the separation between lever upside and releasing mechanism (1-1):

$N>N_{1}$,

$N_{1}=\mu \times F_{1}$.

In the pulling phrase, electromagnet acts on the downside of lever, and generate a force perpetual to lever towards the left in the coordinate system. Given magnetism for specific electromagnet, the stress condition could be derived on the lower part of lever. Based on the force analyses above, the proportion of upper and lower side of lever is designed to 1:8. This proportion could magnify the stress force in maximum and satisfies the need of automatic pulling.

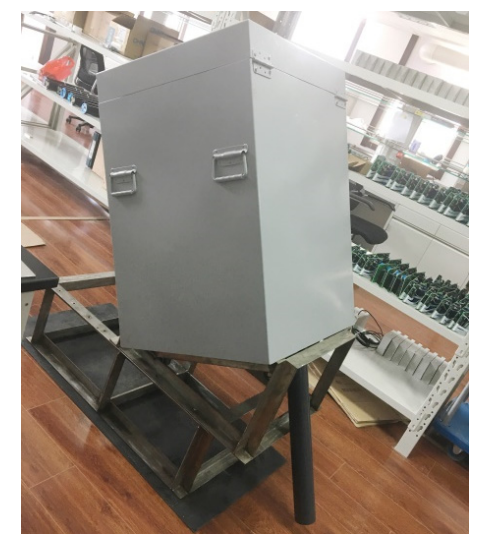

Fig. 4. The installation and debug of automatic launcher of XBT probes

\section{Conclusions}

On the grounds of real needs in marine detection devices, we design a pulling mechanism of probe plug in marine XBT launching system to realize the automatic pulling and recycling of plug of XBT probe. Experiments indoor and outdoor prove the efficiency and reliability of this mechanism. In sea trial, this mechanism avoids the interference of measurement by human and keeps the operators safe. Conclusions are drawn as follow:

1) The core principle is leverage magnification theory. Combining with the force analyses in the plug pulling phrase, we made this plan to make sure lever could magnify the spring elasticity 
in maximum in limited space. Furthermore, automatic pulling of probe plug is realized in marine XBT launching system.

2) This paper analyzes the main structure characters and functions of this pulling mechanism in the whole and the part. The mechanism is established in the need and feature in the marine fieldwork which makes it more practical.

3) The plug pulling mechanism barely involved flexible connection in order to reduce accumulation of error and breakdown in mechanical structures. This pulling mechanism has gone through the vibration tests in Shandong Provincial Key Laboratory of Ocean Environmental Monitoring Technology.

At present, this plug pulling mechanism has been applied into the XBT automatic launching system developed by Institution of Oceanographic Instrumentation of Shandong Academy of Sciences, shown in Fig. 4. In the marine trials near Jiaozhou bay in Qingdao, there are 23 successful tests in the whole experiment of 24 probe droppings. The success rate of measuring is over $95 \%$. The whole XBT automatic launching system only takes $30 \mathrm{~min}$ to drop the whole 24 probes in one trial that spends less than over $50 \%$ man-hours than previous manual dropping. These features meet the needs of quickly releasing and data acquisitions of marine expendable devices. In the future studies, we plan to refine the mechanism structures further and make the mechanism could differentiate probes of different types to realize the mix droppings of XBT and $\mathrm{XCTD}$. That conceiving could raise working efficiency greatly.

\section{References}

[1] Lei Z., He H. J., Qu J. L., et al. Design of high-accuracy temperature measurement circuit of an expendable bathythermograph. Shandong Science, Vol. 27, Issue 4, 2014, p. 8-11.

[2] Xu J. S., Cheng H., Xiang B., et al. Numerical simulation and experimental study of the shape of XBT probe. Journal of Ocean Technology, Vol. 36, Issue 2, 2017, p. 60-64.

[3] Kizu S., Hanawa K. Recorder-dependent temperature error of expendable bathythermograph. Journal of Oceanography, Vol. 58, Issue 3, 2002, p. 469-476.

[4] Cheng L. J., Abraham J., Goni G., et al. XBT Science: assessment of instrumental biases and errors. Bulletin of the American Meteotological Society, Vol. 97, Issue 6, 2015, p. 923-933.

[5] Zappalà G., Reseghetti F., Manzella G. M. R. Development of an automatic multiple launcher for expendable probes. Ocean Science, Vol. 3, 2007, p. 173-178.

[6] Zhang P., Tang S. F., Qu K., et al. Test and analysis on domestic-made XBT probe. Technical Acoustics, Vol. 31, Issue 6, 2012, p. 570-573.

[7] Men Y. B., Fang F., Li X. M., et al. Design of data acquisition and control unit based on multi-XBT probes auto launch and measurement system. Computer Measurement and Control, Vol. 21, Issue 6, 2013, p. 1697-1699.

[8] Chen W. S., Liu M. D., Lei Z. Research on the computational approach of falling depth of an expendable bathythermograph probe in seawater. Shandong Science, Vol. 25, Issue 5, 2012, p. 25-29.

[9] Ren G. X., Wang X. Y., Du L. B. Design of high-precision and fast-response temperature measurement system for ocean. Instrument Technique and Sensor, Vol. 2, 2011, p. 45-47.

[10] Chen G. Y., Qu J. L., Lei Z., et al. An automatic pulling mechanism of probe plug in marine eXpendable BathyThermograph launching system. Chinese Utility Model Patent: ZL $201620864656.2,2017$.

[11] Cao X. R., Zhang S. J., Liu T., et al. Research on the linkage mechanism variation modeling and analysis. Machine Design and Research, Vol. 33, Issue 1, 2017, p. 7-11. 